\title{
Anti-microbial immunity is impaired in COPD patients with frequent exacerbations
}

Aran Singanayagam ${ }^{1}$, Su-Ling Loo ${ }^{2}$, Maria Calderazzo ${ }^{1}$, Lydia J Finney ${ }^{1}$, Maria-Belen Trujillo Torralbo $^{1}$, Eteri Bakhsoliani ${ }^{1}$, Jason Girkin ${ }^{2}$, Punnam Veerati ${ }^{2}$, Prabuddha S Pathinayake $^{2}$, Kristy S Nichol ${ }^{2}$, Andrew Reid ${ }^{2}$, Joseph Foottit ${ }^{1}$, Sebastian L Johnston ${ }^{1}{ }^{*}$, Nathan W Bartlett $^{2 *}$, Patrick Mallia ${ }^{1 *}$

*These authors contributed equally to this work

\section{Affiliations}

1. National Heart and Lung Institute. Imperial College London. UK.

2. Faculty of Health and Medicine and Priority Research Centre for Healthy Lungs. Hunter Medical Research Institute and University of Newcastle. Newcastle. NSW 2305. Australia

Corresponding author: Dr Aran Singanayagam. National Heart and Lung Institute. Imperial College London.

Key words: chronic obstructive pulmonary disease, exacerbation, viral infection, bacterial infection

Word count: 2493

Conflicts of interest:

S.L.J. has personally received consultancy fees from Myelo Therapeutics $\mathrm{GmbH}$, Concert Pharmaceuticals, Bayer, and Sanofi Pasteura, and Aviragen; he and his institution received consultancy fees from Synairgen, Novarits, Boehringer Ingelheim, Chiesi, GlaxoSmithKline, and Centocor. S.L.J. is an inventor on patents on the use of inhaled interferons for treatment of exacerbations of airway diseases. The remaining authors declare no competing interests relevant to this manuscript. 


\section{ABBREVIATIONS}

BECs: bronchial epithelial cells

ALI: air liquid interface

COPD: Chronic obstructive pulmonary disease

FEV1: Forced expiratory volume in 1 second

FVC: Forced vital capacity

GOLD: Global Initiative for Obstructive lung disease

IFN: Interferon

ISG: Interferon-stimulated gene

MBL: Mannose-binding lectin

PEFR: peak expiratory flow rate

RV: rhinovirus

SLPI: Secretory leucocyte protease inhibitor 


\section{ABSTRACT}

Background: Patients with frequent exacerbations represent a chronic obstructive pulmonary disease (COPD) sub-group requiring better treatment options. The aim of this study was to determine the innate immune mechanisms that underlie susceptibility to frequent exacerbations in COPD.

Methods: We measured sputum expression of immune mediators and bacterial loads in samples from patients with COPD at stable state and during virus-associated exacerbations. Ex vivo immune responses to rhinovirus infection in differentiated bronchial epithelial cells (BECs) sampled from patients with COPD were additionally evaluated. Patients were stratified as frequent exacerbators ( $\geq 2$ exacerbations in the preceding year) or infrequent exacerbators ( $<2$ exacerbations in the preceding year) with comparisons made between these groups.

Results: Frequent exacerbators had reduced sputum cell mRNA expression of the anti-viral immune mediators type I and III interferons and reduced interferon-stimulated gene (ISG) expression when clinically stable and during virus-associated exacerbation. RV-induction of interferon and ISGs ex vivo was also impaired in differentiated BECs from frequent exacerbators. Frequent exacerbators also had reduced sputum levels of the anti-microbial peptide mannose-binding lectin (MBL)-2 with an associated increase in sputum bacterial loads at 2 weeks following virus-associated exacerbation onset. MBL-2 levels correlated negatively with bacterial loads during exacerbation.

Conclusion: These data implicate deficient airway innate immunity in the increased propensity to exacerbations observed in some patients with COPD. Therapeutic approaches to boost innate antimicrobial immunity in the lung could be a viable strategy for prevention/treatment of frequent exacerbations. 


\section{INTRODUCTION}

Chronic obstructive pulmonary disease (COPD) is an inflammatory airway disorder in which acute exacerbations represent a major complication. Acute exacerbations are a substantial cause of morbidity and mortality ${ }^{1-3}$ and preventing exacerbations remains a major unmet need. There has been increasing interest in a recently identified sub-group of patients with COPD who are at risk of exacerbations, defined as the 'frequent exacerbator phenotype'. ${ }^{4}$ Patients with frequent exacerbations have worse clinical outcomes including increased morbidity ${ }^{1}$, accelerated lung function decline $^{2}$ and greater mortality ${ }^{5}$, suggesting that this group requires special consideration. To date, the underlying mechanisms that predispose such patients to more frequent exacerbations have not been elucidated. It is plausible that abnormalities in host immunity could underlie an increased propensity to exacerbations.

Viruses are a major aetiological trigger for exacerbations ${ }^{6,7}$ and data exists to suggest that COPD may be associated with deficient anti-viral immunity ${ }^{8,9}$. However, not all studies have shown this abnormality ${ }^{10,11}$, suggesting that it may vary according to disease phenotype. Frequent exacerbators could represent one sub-group in whom defective anti-viral immunity is more prominent. Both experimental and naturally-occurring exacerbation studies also confirm that an initial virus infection can precipitate secondary bacterial infection in COPD ${ }^{12,13}$ with neutrophil elastase-induced cleavage of anti-microbial peptides believed to be important mechanistically ${ }^{12}$. Although bacterial colonisation at stable state has been shown to be associated with increased exacerbation frequency ${ }^{14}$, antimicrobial peptide responses and propensity to develop secondary bacterial infection during virusinfections in frequent versus infrequent exacerbators has not previously been studied.

We hypothesised that patients with COPD who have a history of frequent exacerbations would have impaired anti-viral and/or anti-bacterial immunity compared to infrequent exacerbators. Using analysis of sputum samples from a cohort of patients monitored prospectively in the community, in combination with in vitro experiments in BECs sampled from patients with COPD and differentiated at the air-liquid interface (ALI), we show that lung innate anti-microbial immunity is impaired in frequent exacerbators. These mechanisms may underlie the increased propensity to exacerbation observed in some patients. 


\section{METHODS}

\section{The St Mary's Hospital naturally-occurring COPD exacerbation cohort}

A cohort of 40 COPD subjects was recruited to a longitudinal study carried out at St Mary's Hospital, London UK between June 2011 to December 2013 investigating the pathogenesis of naturallyoccurring COPD exacerbations. The study protocol was approved by the East London Research Ethics Committee (study number 11/LO/0229) and all subjects gave informed written consent. The subjects all had a clinical diagnosis of COPD that was confirmed with spirometry. All subjects had an initial visit at baseline when clinically stable for clinical assessment, spirometry (forced expiratory volume in 1 second $\left(\mathrm{FEV}_{1}\right)$, forced vital capacity (FVC) and peak expiratory flow (PEF)) and clinical sample collection including spontaneous or induced sputum, taken and processed as previously described ${ }^{8,15}$. At the baseline visit, all subjects were asked about the number of exacerbations experienced in the previous year and were grouped into two groups - frequent exacerbators ( $\geq 2$ exacerbations in preceding year) and infrequent exacerbators ( $0-1$ exacerbations in the previous year), as previously described ${ }^{16}$. Subjects then had repeat visits at three monthly intervals when clinically stable and were followed up for a minimum of 6 months. Subjects reported to the study team when they developed symptoms of an upper respiratory tract infection or an increase in any of the symptoms of dyspnoea, cough, sputum volume or purulence. Exacerbation was defined using the East London cohort criteria. ${ }^{2}$ Subjects were seen within 48 hours of onset of their symptoms for collection of samples and repeat visits was carried out a two weeks after the initial exacerbation visit. Samples from this cohort have been used in a previous study investigating the role of airway glucose in COPD ${ }^{17}$

\section{Experimental challenge studies}

For baseline analyses of sputum soluble mediators, in addition to samples taken from the naturally occurring exacerbation study, we also included baseline (pre-infection) samples from 14 COPD subjects recruited to experimental challenge COPD studies ${ }^{8,18}$. All subjects in these studies gave informed written consent and the protocol was approved by St Mary's NHS Trust Research Ethics Committee (study numbers 00/BA/459E and 07/H0712/138). These subjects were characterised as frequent or infrequent exacerbators using the same definition as described above. Sputum samples were processed using exactly the same methodology as described in the naturally occurring exacerbation study. 


\section{RV infection of air-liquid interface differentiated bronchial epithelial cells from patients with COPD}

Primary BECs obtained bronchoscopically from patients with COPD (GOLD Stage II or III) were grown until confluent and differentiated at air liquid-interface (ALI), as previously described ${ }^{19-21}$. All subjects included gave informed written consent and the study protocol was approved by the Hunter New England Human Research Ethics Committee (05/08/10/3.09). Primary cells were grown in complete bronchial epithelial cell growth medium (BEGM)(Lonza) with growth factor supplements in submerged monolayer culture and then seeded at $2 \times 10^{5}$ cells $/ \mathrm{mL}$ in transwells until confluent. RV-A1 infection (MOI 0.1) was applied to the apical surface for 2 hours in $250 \mu \mathrm{l}$ bronchial epithelial basal medium (BEBM) minimal at $35^{\circ} \mathrm{C}$. Following this, infection media was replaced with $500 \mu \mathrm{l}$ fresh BEBM minimal for the remainder of the experiment. Samples were collected at 72 hours post-infection with apical media removed and stored for protein expression analyses. Type III IFN proteins were measured using a custom-designed LEGENDplex kit (BioLegend). IFN- $\beta$ was measured using the Verikine ELISA (PBL). Half of the transwell membrane was also carefully cut from the inserts and collected into RLT buffer (Qiagen) containing 1\% 2-mercaptoethanol for downstream molecular analyses by RT-qPCR. The remaining transwell membrane was fixed in 10\% neutral-buffered formalin for 24 hours for histological cross-sections to confirm differentiation.

\section{Measurement of sputum proteins}

Protein levels in cell-free sputum samples of CXCL10/IP-10 and CCL5/RANTES were measured using duoset ELISA kits (R\&D Systems), according to manufacturer's instructions. Protein levels of all antimicrobial peptides were assayed using commercial ELISA assay kits, as previously described ${ }^{12,22}$. The sources of the individual ELISAs were as follows: Elafin (R\&D Systems), Mannose binding lectin (MBL)2 (R\&D Systems) and SLPI (R\&D Systems).

\section{RNA extraction, cDNA synthesis and quantitative PCR}

Total RNA was extracted from sputum cell pellets or bronchial epithelial cell lysates stored in RLT buffer (RNeasy kit, Qiagen) and $2 \mu \mathrm{g}$ was used for cDNA synthesis (Omniscript RT kit). Quantitative PCR was carried out using previously described specific primers and probes for each gene of interest ${ }^{23}$, and normalized to $18 \mathrm{~S}$ rRNA. Reactions were analysed using $A B I 7500$ Fast Realtime PCR system (Applied Biosystems, Carlsbad, CA). 


\section{Virus detection, DNA extraction and bacterial 165 quantitative PCR}

DNA extraction from total sputum was performed using the FastDNA Spin Kit for Soil (MP Biomedicals, Santa Ana, USA), as per manufacturer instructions. Bead-beating was performed for two cycles of 30 seconds at $6800 \mathrm{rpm}$ (Precellys, Bertin Technologies, Montigny-le-Bretonneux, France). Total 16S bacterial loads were measured using quantitative $P C R$, as previously described ${ }^{24}$. Viruses were detected as described previously ${ }^{12}$.

\section{Statistical Analyses}

Comparisons of sputum mRNA expression and protein concentrations between frequent and infrequent exacerbators were analysed using the Mann-Whitney $U$ test. For in vitro experiments, baseline versus RV-induced expression was analysed using Wilcoxon rank-sum test. Mann Whitney $U$ test was used to compare RV induction of mRNA or proteins between frequent and infrequent exacerbators. Correlations between datasets were examined using Spearman's rank correlation coefficient. All statistics were performed using GraphPad Prism 6 software. Differences were considered significant when $P<0.05$. 


\section{RESULTS}

\section{Study population}

We utilised a community-based cohort of COPD patients to evaluate anti-microbial immunity at baseline (stable-state) and during virus associated exacerbation. For baseline analyses of sputum cell mRNA (interferons (IFNs) and interferon-stimualated genes (ISGs)), 36 patients had sufficient sample for evaluation and, of these, 13 patients (36.1\%) were classified as frequent exacerbators (clinical characteristics are shown in table 1). For baseline analyses of sputum soluble mediators (CXCL10/IP10, MBL, SLPI and elafin proteins), samples from a total of 50 COPD patients (combined from the community cohort and from subjects recruited to experimental infection studies) were available, with 15 patients (30\%) classified as frequent exacerbators (clinical characteristics are also shown in table 1).

\section{Evaluation of baseline expression of anti-viral mediators}

Since viruses are a major cause of exacerbations and deficient anti-viral immunity has been observed in some but not all studies of COPD ${ }^{8-11}$, we hypothesised that frequent exacerbators would have reduced baseline expression of anti-viral immune mediators and thus an impaired potential to mount protective responses to virus infections. We examined baseline sputum cell mRNA expression of type I and III IFNs and ISGs in 36 patients from the community-based COPD cohort and found that frequent exacerbators had significantly reduced sputum IFNB and IFN $2 / 3$ mRNA expression with no difference in IFN $\lambda 1$ (Figure 1a). Baseline sputum concentrations of the interferon-inducible protein CXCL10/IP10 (Figure 1b) were also reduced in frequent exacerbators but no difference in mRNA expression of other ISGs 2'-5' OAS, viperin or Mx1 was observed (Figure 1c).

\section{Sputum interferon and ISG expression during virus positive exacerbation}

In the community-based cohort, 18 episodes of acute exacerbation with positive virus detection were observed (rhinovirus $n=11$, coronavirus $n=4, R S V n=2$, influenza $n=1$ ). Of these, $n=7(38.9 \%$ ) occurred in patients classified as frequent exacerbators. Clinical characteristics of the exacerbating patients are shown in table 2. One patient was hospitalised during exacerbation with all other episodes treated in the community. Having observed that frequent exacerbators have reduced capacity to mount an innate anti-viral response at stable state, we next examined sputum cell mRNA expression of IFNs and ISGs in the sub-group of patients who developed an exacerbation associated with positive virus detection. Frequent exacerbators had significantly reduced sputum cell expression of IFNB, IFN $\lambda 2 / 3$ and IFN 1 mRNAs at exacerbation presentation (Figure 2a). Sputum 2'-5'OAS mRNA expression was also significantly reduced at exacerbation presentation in frequent versus infrequent exacerbators 
with no differences observed for viperin or $M x 1$ expression (Figure $2 b$ ). Frequent exacerbators also had reduced sputum concentrations of the interferon-inducible cytokine CXCL10/IP-10 at exacerbation onset and 2 weeks post-onset with a similar non-significant trend $(P=0.25)$ observed at exacerbation onset for CCL5/RANTES (Figure 2c).

\section{Ex vivo bronchial epithelial anti-viral responses to $\mathrm{RV}$ infection are attenuated in frequent exacerbators}

Having observed reduced IFN- and ISG-expression in frequent exacerbators from in vivo sputum samples taken during exacerbation, we next proceeded to determine whether epithelial cells from patients with COPD who are frequent exacerbators have deficient innate responses to RV infection. We utilised BECs collected bronchoscopically from sixteen patients with COPD ( $n=9$ frequent exacerbators, $n=7$ infrequent exacerbators), differentiated at an air liquid interface and infected with $\mathrm{RV}-\mathrm{A} 1$ at $\mathrm{MOI}=0.1$. Demographic/clinical characteristics of the included patients are shown in Table 3.

Greater heterogeneity with trend for increased viral load was observed in BECs from frequent exacerbators (Supplementary Fig 1). Significant induction of IFNB and IFN $\lambda 1$ and IFN $\lambda 2 / 3$ mRNAs from baseline was observed in both frequent and infrequent exacerbators at 72 hours post-infection (Figure 3a). RV induction of IFN 1 mRNA was significantly lower in frequent versus infrequent exacerbators with a similar trend $(P=0.29)$ observed for IFNB mRNA but no significance difference observed for IFN $2 / 3$ (Fig 3a). RV induction of the ISGs $2^{\prime}-5^{\prime} O A S$ and Viperin mRNA was also significantly lower in frequent versus exacerbators with no significant difference observed for $P K R$ (Figure $3 b$ ).

Significant induction of IFN- $\beta$, IFN- $\lambda 1$ or IFN $-\lambda 2 / 3$ proteins from baseline was also observed in both frequent and infrequent exacerbators at 72 hours post-infection (Figure 3c). However, there were no significant differences in the induction of IFN- $\beta$, IFN- $\lambda 1$ or IFN- $\lambda 2 / 3$ proteins by RV between frequent and infrequent exacerbators at 72 hours post-infection (Figure 3c).

Collectively, these data supported our in vivo findings from exacerbating patients that anti-viral responses are reduced in frequent exacerbators and extended these observations by identifying a dysregulated innate immune response in BECs defined by impaired expression of IFN and ISGs 


\section{Evaluation of sputum bacterial loads at baseline and during virus-associated exacerbation}

Virus-induced exacerbation can trigger subsequent bacterial infection in COPD $^{12,13}$, a secondary phenomenon that is associated with increased exacerbation severity ${ }^{12}$ and inversely related to the interferon responses ${ }^{21}$. Having observed that anti-viral immunity is reduced in frequent exacerbators both in vivo and primary BECs from patients with COPD in vitro, we next examined whether sputum bacterial loads at stable state and during exacerbation differed according to exacerbation frequency. There were no differences in sputum $16 \mathrm{~S}$ bacterial loads between frequent and infrequent exacerbators at baseline or exacerbation onset (Fig 4a\&b). However, frequent exacerbators had a significant increase ( $1 \mathrm{log}$ ) in bacterial loads at 2 weeks post exacerbation onset (Fig $4 \mathrm{c})$, suggesting that this COPD subgroup may have increased likelihood of secondary bacterial infection during virusinduced exacerbation.

\section{No difference SLPI or elafin levels between frequent and infrequent exacerbators}

We have previously reported that rhinovirus-induced secondary bacterial infection occurs through neutrophil elastase-mediated cleavage and reduction of the anti-microbial peptides (AMPS) SLPI and elafin, a process that occurs in COPD but not healthy subjects and may be further accentuated by inhaled corticosteroid use ${ }^{21}$. Given our observation of increased bacterial loads in frequent exacerbators, we next examined whether this sub-group of COPD patients have concurrently reduced SLPI and elafin levels. There were no differences in sputum SLPI or elafin levels between frequent and infrequent exacerbators either at baseline (Supplementary Fig 2a-b) or during exacerbation (Supplementary Fig 1c-d). This suggested that differential expression of these AMPs does not underlie increased secondary bacterial infection in frequent exacerbators.

\section{Airway mannose-binding lectin 2 levels are reduced in frequent exacerbators at baseline and during virus-associated exacerbation}

We next focused on other another AMP that could be important in driving secondary bacterial infection in COPD. A previous study reported that mannose-binding lectin (MBL)-2 polymorphisms with associated MBL-2 deficiency in serum is associated with recurrence of infective exacerbations in COPD ${ }^{25}$. Consistent with this report, we also found that MBL-2 concentrations in sputum were significantly reduced in frequent versus infrequent exacerbators at stable state (Figure 5a) and also at 2 weeks post exacerbation onset (Figure $5 b$ ), the same timepoint at which bacterial loads were increased. 


\section{Airway mannose-binding lectin 2 levels negatively correlates with bacterial loads during virus- associated exacerbation}

Having observed that frequent exacerbators have reduced MBL-2 levels and increased bacterial loads at 2 weeks post exacerbation onset, we next examined the relationship between these variables. There was a significant negative correlation between sputum concentrations of MBL-2 and bacterial loads (Figure 5c) suggesting that lower MBL-2 levels may contribute to increased secondary bacterial infection in frequent exacerbators.

\section{DISCUSSION}

The underlying mechanisms involved in increased susceptibility to frequent exacerbations remains a crucial research question in COPD. We show here, for the first time, that patients with COPD who have a history of frequent exacerbations have reduced airway anti-microbial immunity when assessed at clinical stability and during subsequent virus-associated exacerbation with an associated increase in bacterial loads. We additionally confirm that COPD frequent exacerbators have reduced ex vivo immune responses to $\mathrm{RV}$ infection in primary airway epithelial cells, indicating an innate anti-viral deficiency. This is the first study to show that frequent exacerbators have impaired airway antimicrobial responses and provides an important mechanistic advance in our understanding of this clinically important COPD sub-group. These abnormalities could predispose such patients to greater risk of acquisition of pathogenic viruses and bacteria and/or promote a greater likelihood of developing an exacerbation following infection.

Previous studies have shown that ex vivo type I IFN responses to RV infection in bronchoalveolar cells and to influenza infection in BECs are impaired in COPD ${ }^{8,9}$. Patients with COPD also have increased virus loads and enhanced exacerbation severity when experimentally infected with rhinovirus ${ }^{8,18}$. However, defects in anti-viral immunity have not been shown universally with other studies reporting the opposite effect of augmented ex vivo anti-viral responses in COPD ${ }^{10,11}$. The discrepancy between these COPD studies suggests that defective immunity may not be present in all patients with a number of confounding competing factors such as disease severity and medications likely to have an influence. It is plausible that patients with frequent exacerbations might represent one sub-group with impaired anti-viral immunity. We report here that expression of both type I and type III IFNs, IFNB and IFN 2/3 mRNAs is reduced in frequent exacerbators at stable state, suggesting that these patients might have a reduced potential to generate protective responses to virus infection. In support of this hypothesis, we also observed that anti-viral responses including IFNB, IFN $\lambda 1$ and IFN $2 / 3$ and the ISGs $2^{\prime}-5^{\prime} O A S$ 
and CXCL10/IP-10 were suppressed during exacerbations in frequent exacerbators and that RVinduction of IFN $1,2^{\prime}-5^{\prime} O A S$ and Viperin mRNAs in BECs ex vivo was also reduced in frequent exacerbators.

Our study provides the first evidence that frequent exacerbators have innate anti-viral immune dysfunction, suggesting that a reduction in interferon production might underlie an augmented propensity to virus infections and thus increased exacerbation frequency observed in these patients. This mechanism is supported by a clinical study which reported that COPD patients who are frequent exacerbators experience significantly more coryzal episodes than infrequent exacerbators ${ }^{26}$. Given that inhaled IFN- $\beta$ therapy has been shown to confer clinical benefit in a subgroup of severe asthmatic patients who develop a cold ${ }^{27}$, our data raises suggestion that such innate immune-boosting therapies could be effective when used in a targeted manner in patients with COPD with evidence of frequent exacerbations and a less effective innate immune response.

Despite observing impaired ex vivo RV-induction of IFN and ISG mRNA in frequent exacerbator BECS at 72 hours post-infection, we did not observe corresponding differences in protein production of type I and III IFNs by these cells at the same timepoint. Our studies were limited by sample availability only allowing evaluation at a single timepoint. We have previously reported that protein production of IFN persists at least up to 96 hours in this cell type ${ }^{21}$ and it is feasible that evaluation at later timepoints may be required to observe significant differences in translated IFN proteins. Despite a lack of difference in absolute levels of IFN protein, the reduced ISG expression observed in frequent exacerbators supports a less effective IFN-induced response in these subjects

Bacterial infection is also associated with exacerbation in COPD with increased PCR-based bacterial detection at exacerbation versus stable state suggesting a causative role ${ }^{28,29}$. Additionally, virusinduced secondary bacterial infection has been reported in both experimental and naturally occurring exacerbations ${ }^{12,13}$. We have previously reported that experimental $\mathrm{RV}$ challenge in patients with COPD is associated with increased frequency of secondary bacterial infection compared to healthy subjects ${ }^{12,30}$ via a mechanism of neutrophil elastase-mediated cleavage of anti-microbial peptides SLPI and elafin ${ }^{12}$. Here, we extend these findings to reveal that frequent exacerbators have higher bacterial loads at 2 weeks following onset of virus-associated exacerbation, suggesting that this subgroup of COPD patients might be at greatest risk of developing secondary bacterial infection following initial virus infection. Although we found no difference in levels of SLPI and elafin according to exacerbation frequency, we did identify that expression of another AMP MBL-2 was reduced in frequent 
exacerbators at stable state and during virus positive exacerbation. The potential importance of MBL2 during virus-associated exacerbation was further demonstrated by our finding that its expression correlated negatively with bacterial loads during exacerbation. MBL is a key component of innate immunity that activates the lectin complement pathway and is involved in the process of bacterial phagocytosis ${ }^{31}$. MBL deficiency is associated with susceptibility to respiratory tract infections and pneumonia in healthy individuals ${ }^{32,33}$ and to increased risk of sepsis in animal models ${ }^{34}$. MBL can bind to various pathogens of relevance to COPD exacerbations including both viruses and bacteria ${ }^{35}$. Genetic MBL deficiency has been previously shown to be associated with both increased ${ }^{25,36}$ and reduced $^{37}$ exacerbation frequency in COPD. Although serum MBL concentrations have been shown to not differ between frequent and infrequent exacerbators ${ }^{36}$, a previous study reported reduced bronchoalveolar lavage MBL concentrations in COPD versus healthy subjects ${ }^{38}$. Our data extends these observations by demonstrating that deficient airway MBL-2 at baseline and during subsequent exacerbation might predispose frequent exacerbators to increased secondary bacterial infection. A previous study reported that the presence of rhinovirus is associated with increased S.pneumoniae colonization in children with MBL gene polymorphisms, further suggesting a role for MBL in virusinduced secondary bacterial infection ${ }^{39}$. Given that nebulised plasma-derived MBL has been shown to restore phagocytic function in smoke-exposed mice ${ }^{40}$, our data raise speculation that administration of MBL could additionally be considered as an effective preventative and/or therapeutic strategy for COPD exacerbations. Further studies are needed to evaluate this.

It is important to note that causation cannot be inferred from the results of our study. Although we found reduced anti-microbial responses in patients with a history of frequent exacerbations, we cannot reliable conclude that these abnormalities directly lead to inherent increased exacerbation risk per se. There are likely to be a number of additional factors that may be contributing to the observed differences and, notably, in stable state analyses, frequent exacerbators showed trends towards greater ICS use and less current smoking. These confounders could contribute directly or indirectly to the differences observed, as previously reported ${ }^{21,41,42}$. We therefore consider our study to be hypothesis generating and emphasise the importance of future larger in vivo studies to more carefully dissect the influence of various factors and definitely answer the question of whether deficient antimicrobial immunity underlies propensity to exacerbation frequency in COPD. Previous studies have also indicated that exacerbation risk in COPD is dynamic and may change from year to year ${ }^{4,43}$. A longer-term study with repeated airway sampling would be need to determine whether baseline antimicrobial responses are similarly dynamic in nature. 
In conclusion, we show that patients with COPD and a history of frequent exacerbations have reduced anti-viral and anti-bacterial immunity associated with increased secondary bacterial infection. These immune defects may underlie the increased propensity to exacerbations observed in this sub-group and provides evidence to support therapeutic approaches that boost innate immunity in COPD 


\section{TABLES}

\section{Patients included in baseline mRNA analyses $(n=36)$}

\begin{tabular}{|l|l|l|l|}
\hline & $\begin{array}{l}\text { Frequent } \\
\text { exacerbators } \\
(\mathbf{n = 1 3 )}\end{array}$ & $\begin{array}{l}\text { Infrequent } \\
\text { exacerbators } \\
(\mathbf{n}=\mathbf{2 3})\end{array}$ & P value \\
\hline Male sex & $10(66.7 \%)$ & $27(77.1 \%)$ & 0.49 \\
\hline Age & $68.5(58.3-75.3)$ & $67(59.0-71.5)$ & 0.69 \\
\hline GOLD stage I/II/III/IV & $0 / 9 / 3 / 3$ & $5 / 28 / 2 / 0$ & \\
\hline Long term oxygen use & $1(6.7 \%)$ & $0(0 \%)$ & 0.30 \\
\hline Cardiac disease & $4(26.7 \%)$ & $2(5.7 \%)$ & 0.058 \\
\hline Cerebrovascular disease & $3(20 \%)$ & $1(2.9 \%)$ & 0.075 \\
\hline Diabetes & $2(13.3 \%)$ & $2(5.7 \%)$ & 0.57 \\
\hline $\begin{array}{l}\text { Pulmonary } \\
\text { hypertension }\end{array}$ & $0(0 \%)$ & $1(2.9 \%)$ & 1.0 \\
\hline $\begin{array}{l}\text { Inhaled corticosteroid } \\
\text { use }\end{array}$ & $9(56.3 \%)$ & $11(31.4 \%)$ & 0.11 \\
\hline Beta agonist use & $14(93.3 \%)$ & $18(51.4 \%)$ & 0.0046 \\
\hline $\begin{array}{l}\text { Anti-muscarinic inhaler } \\
\text { use }\end{array}$ & $12(80.0 \%)$ & $12(34.3 \%)$ & 0.0049 \\
\hline Current smoker & $6(40.0 \%)$ & $7(20.0 \%)$ & 0.17 \\
\hline
\end{tabular}

Patients included in baseline sputum soluble mediator analyses $(n=50)$

\begin{tabular}{|c|c|c|c|}
\hline & $\begin{array}{l}\text { Frequent } \\
\text { exacerbators } \\
(n=15)\end{array}$ & $\begin{array}{l}\text { Infrequent } \\
\text { exacerbators } \\
(n=35)\end{array}$ & $P$ value \\
\hline Male sex & $10(66.7 \%)$ & $27(77.1 \%)$ & 0.49 \\
\hline Age & $68.5(58.3-75.3)$ & 67 (59.0-71.5) & 0.69 \\
\hline GOLD stage $1 / I I / I I I / I V$ & $0 / 9 / 3 / 3$ & $5 / 28 / 2 / 0$ & \\
\hline Long term oxygen use & $1(6.7 \%)$ & $0(0 \%)$ & 0.30 \\
\hline Cardiac disease & $4(26.7 \%)$ & $2(5.7 \%)$ & 0.058 \\
\hline Cerebrovascular disease & $3(20 \%)$ & $1(2.9 \%)$ & 0.075 \\
\hline Diabetes & $2(13.3 \%)$ & $2(5.7 \%)$ & 0.57 \\
\hline $\begin{array}{l}\text { Pulmonary } \\
\text { hypertension }\end{array}$ & $0(0 \%)$ & $1(2.9 \%)$ & 1.0 \\
\hline $\begin{array}{l}\text { Inhaled corticosteroid } \\
\text { use }\end{array}$ & $9(56.3 \%)$ & $11(31.4 \%)$ & 0.11 \\
\hline Beta agonist use & $14(93.3 \%)$ & $18(51.4 \%)$ & 0.0046 \\
\hline $\begin{array}{l}\text { Anti-muscarinic inhaler } \\
\text { use }\end{array}$ & $12(80.0 \%)$ & $12(34.3 \%)$ & 0.0049 \\
\hline Current smoker & $6(40.0 \%)$ & $7(20.0 \%)$ & 0.17 \\
\hline
\end{tabular}




\begin{tabular}{|l|l|l|l|}
\hline & $\begin{array}{l}\text { Frequent exacerbators } \\
(\mathbf{n}=\mathbf{7})\end{array}$ & $\begin{array}{l}\text { Infrequent } \\
\text { exacerbations (n=11) }\end{array}$ & P value \\
\hline $\begin{array}{l}\text { Age } \\
\text { (median (IQR)) }\end{array}$ & $69(64-74)$ & $71(52-76)$ & 0.84 \\
\hline Male sex & $3(42.9 \%)$ & $9(81.8 \%)$ & 0.14 \\
\hline $\begin{array}{l}\text { GOLD Stage } \\
\text { (median (IQR)) }\end{array}$ & $2(2-3)$ & $2(1-2)$ & 0.13 \\
\hline Long term oxygen & $0(0 \%)$ & $0(0 \%)$ & 1.0 \\
\hline Cardiac disease & $0(0 \%)$ & $1(9.1 \%)$ & 1.0 \\
\hline $\begin{array}{l}\text { Cerebrovascular } \\
\text { disease }\end{array}$ & $1(14.3 \%)$ & $0(0 \%)$ & 0.39 \\
\hline Diabetes & $1(14.3 \%)$ & $1(9.1 \%)$ & 1.0 \\
\hline $\begin{array}{l}\text { Pulmonary } \\
\text { hypertension }\end{array}$ & $0(0 \%)$ & $0(0 \%)$ & 1.0 \\
\hline $\begin{array}{l}\text { Inhaled } \\
\text { corticosteroid use }\end{array}$ & $4(57.1 \%)$ & $3(27.3 \%)$ & 0.33 \\
\hline Beta agonist use & $6(85.7 \%)$ & $7(63.6 \%)$ & 0.60 \\
\hline $\begin{array}{l}\text { Anti-muscarinic } \\
\text { inhaler use }\end{array}$ & $4(57.1 \%)$ & $6(54.5 \%)$ & 1.0 \\
\hline Current smoker & $4(57.1 \%)$ & $2(18.2 \%)$ & $\begin{array}{l}0.15 \\
0.043\end{array}$ \\
\hline $\begin{array}{l}\text { Treatments during } \\
\text { exacerbation } \\
\text { Antibiotics } \\
\text { Oral corticosteroids }\end{array}$ & \begin{tabular}{l}
$5(71.1 \%)$ \\
\hline $\begin{array}{l}\text { Table 2: Characteristics of patients who developed virus associated exacerbation stratified } \\
\text { according to exacerbation frequency. }\end{array}$
\end{tabular} & $\begin{array}{l}3(27.3 \%) \\
0(0 \%)\end{array}$ \\
\hline
\end{tabular}




\begin{tabular}{|l|l|l|l|}
\hline & $\begin{array}{l}\text { Frequent } \\
\text { exacerbators }(\mathbf{n}=9)\end{array}$ & $\begin{array}{l}\text { Infrequent } \\
\text { exacerbations (n=7) }\end{array}$ & P value \\
\hline Age & $77(72.5-82)$ & $67(63.5-71)$ & 0.29 \\
\hline $\begin{array}{l}\text { GOLD stage } \\
\mathbf{3}\end{array}$ & $\begin{array}{l}1(11.1 \%) \\
8(88.9 \%)\end{array}$ & $\begin{array}{l}2(28.6 \%) \\
6(85.7 \%)\end{array}$ & $\begin{array}{l}0.55 \\
1.0\end{array}$ \\
\hline Male sex & $6(66.7 \%)$ & $3(42.9 \%)$ & 0.61 \\
\hline $\begin{array}{l}\text { Inhaled corticosteroid } \\
\text { use }\end{array}$ & $7(77.8 \%)$ & $3(42.9 \%$ & 0.30 \\
\hline $\begin{array}{l}\text { Long acting Beta } \\
\text { agonist use }\end{array}$ & $7(77.8 \%)$ & $3(42.9 \%)$ & 0.30 \\
\hline $\begin{array}{l}\text { Anti-muscarinic } \\
\text { inhaler use }\end{array}$ & $7(77.8 \%)$ & $3(42.9 \%)$ & 0.30 \\
\hline \multicolumn{2}{|l|}{$\begin{array}{l}\text { Current smoker } \\
\text { airway epithelial cell experiments shown in figure 5. }\end{array}$} & 0.26 \\
\hline
\end{tabular}




\section{FIGURES LEGENDS}

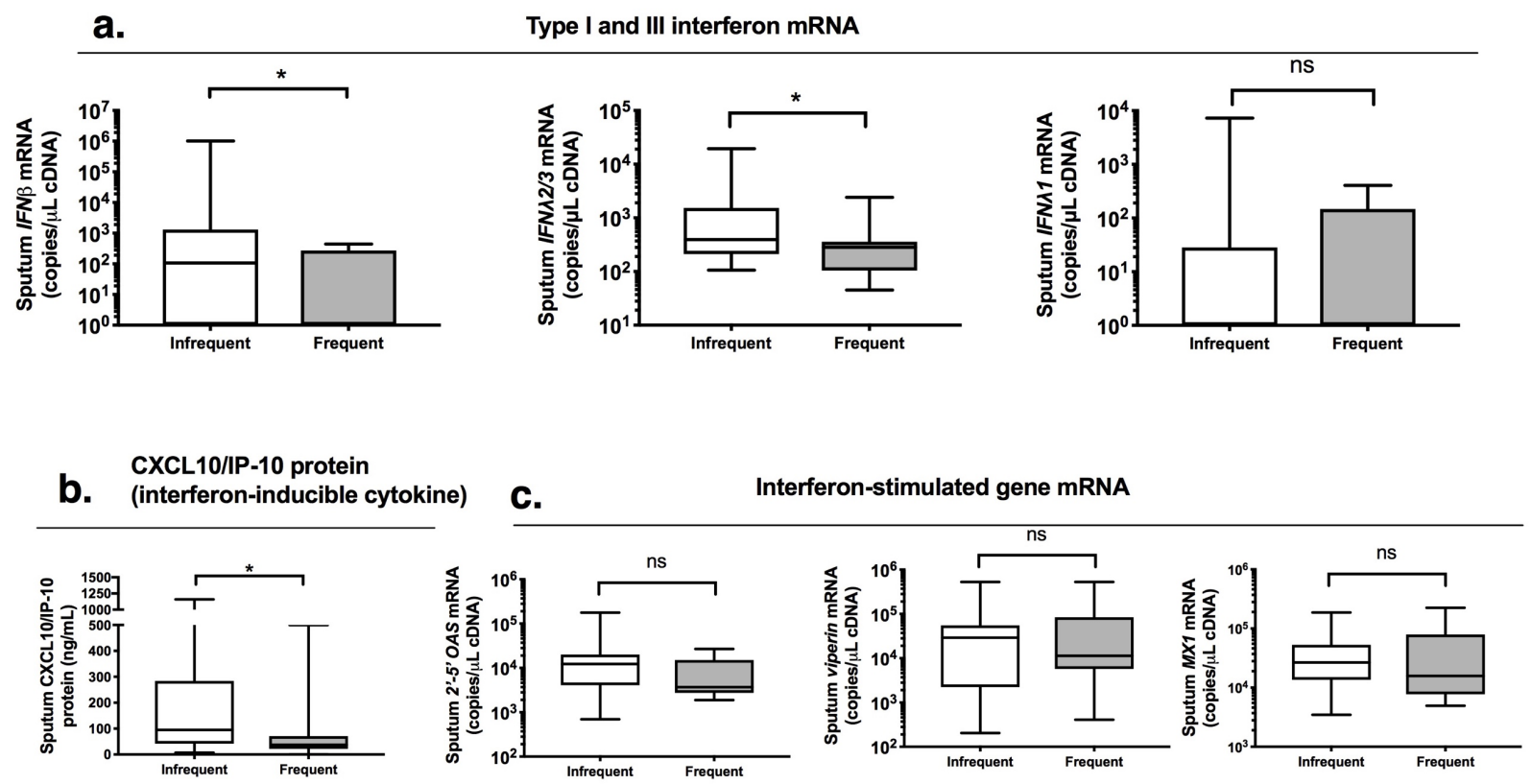

Figure 1: COPD patients with frequent exacerbations have reduced anti-viral immunity at clinical stability. A cohort of patients with COPD were monitored prospectively and sputum samples were taken when clinically stable for at least 6 weeks. Patients were stratified according to exacerbation frequency in the preceding year with patients who experienced $\geq 2$ exacerbation episodes classified as 'frequent'. Sputum cell mRNA expression of (a) IFNB, IFN $2 / 3$ and IFN $\lambda 1$ was measured by quantitative PCR. (b) Sputum supernatant protein concentrations of CXCL10/IP-10 were measured by ELISA. Sputum cell mRNA expression of interferon-stimulated genes (ISGs) (c) 2'-5'OAS, viperin and $M \times 1$ was measured by quantitative PCR. Box and whisker plots showing median (line within box), IQR (box) and minimum to maximum (whiskers). Statistical comparisons were made using Mann Whitney $\mathrm{U}$ test. ${ }^{*} \mathrm{p}<0.05$. ns $=$ non-significant. 
a. Type I and III interferon mRNA
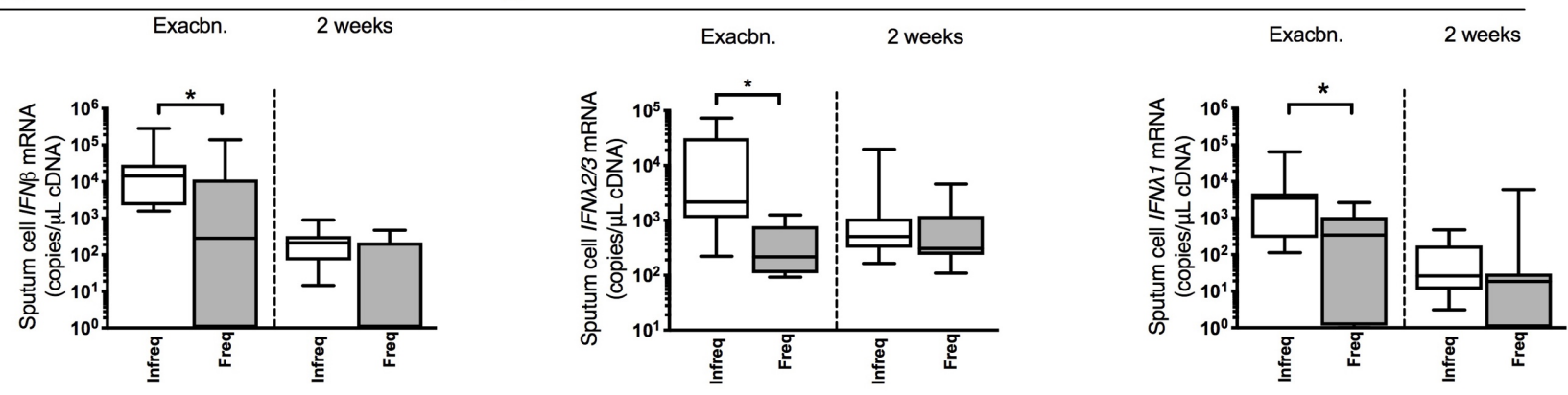

b.

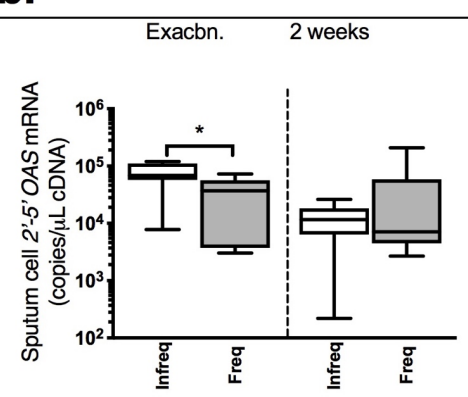

Interferon stimulated gene mRNA

C.
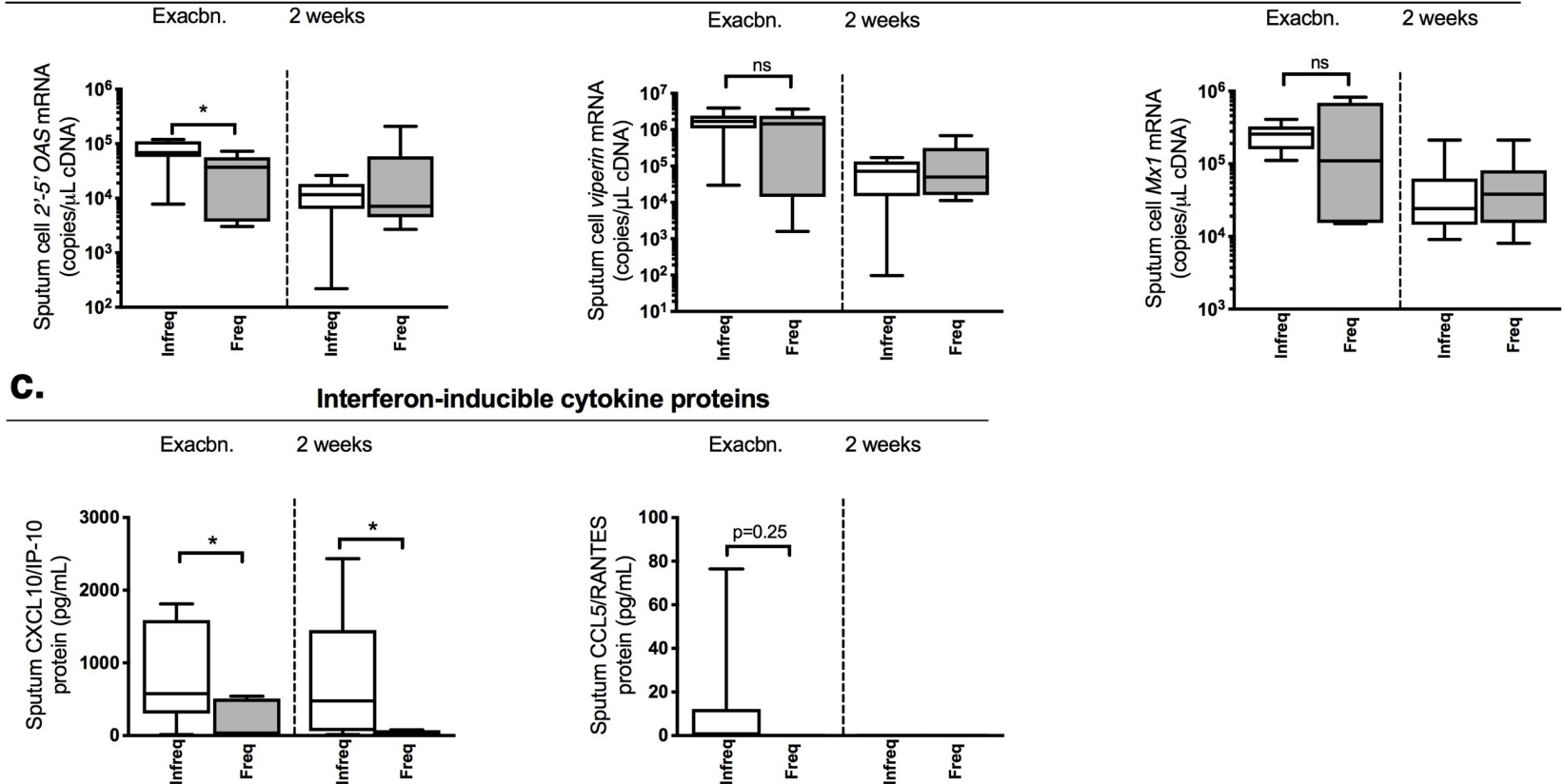

Figure 2: COPD patients with frequent exacerbations have reduced anti-viral immunity during virus-associated naturally occurring exacerbations. A cohort of patients with COPD were monitored prospectively. Patients were stratified according to exacerbation frequency in the preceding year with patients who experienced $\geq 2$ exacerbation episodes classified as 'frequent'. Sputum samples were taken at presentation with exacerbation associated with positive virus detection and 2 weeks during exacerbation. Sputum mRNA expression of (a) IFNB, IFN $2 / 3$ and IFN $\lambda 1$ (b) 2'-5'OAS, viperin and $M \times 1$ was measured by quantitative PCR. Sputum protein concentrations of (c) CXCL10/IP-10 and CCL5/RANTES were measured by ELISA. Data displayed as box and whisker plots showing median (line within box), IQR (box) and minimum to maximum (whiskers). Statistical comparisons were made using Mann Whitney $U$ test. ${ }^{*} p<0.05$. ns = non-significant. 
a. Type I and III interferon mRNA
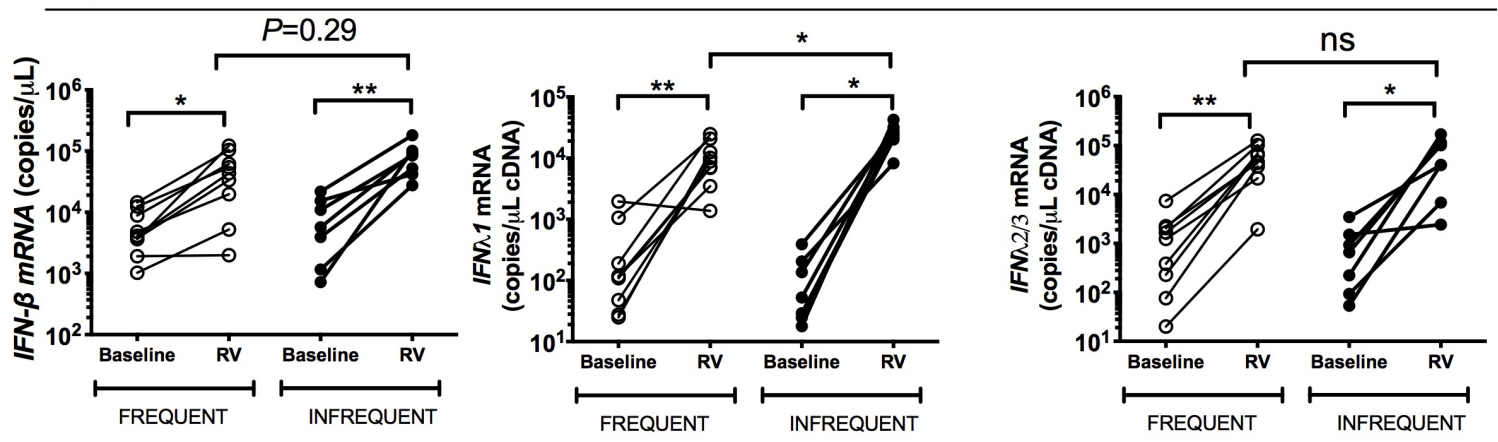

b.

Interferon stimulated gene mRNA
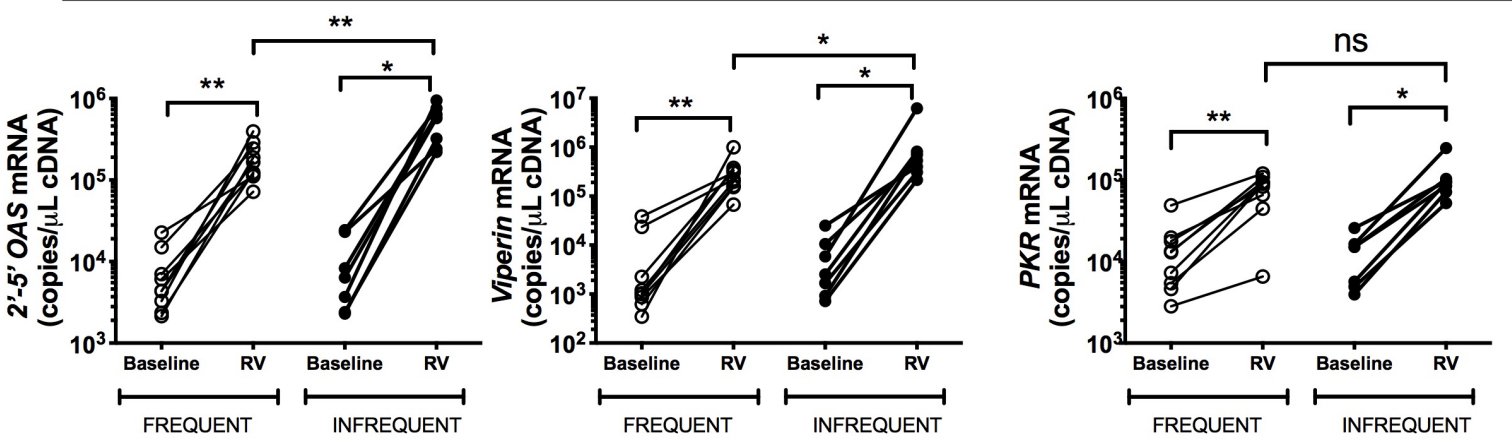

C.

Type I and III interferon protein
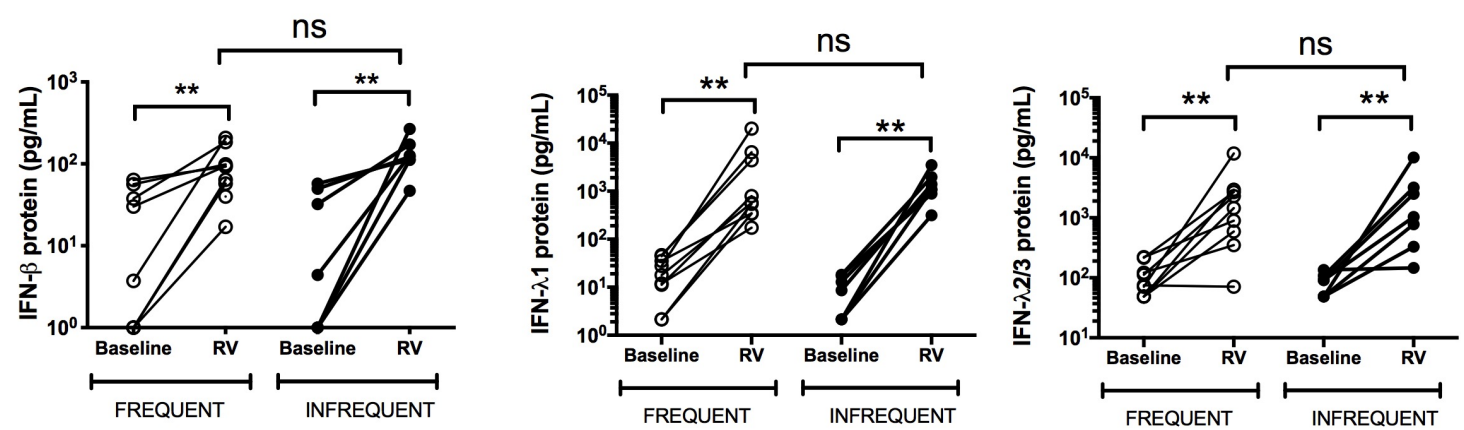

Figure 3: COPD patients with frequent exacerbations have deficient ex vivo innate anti-viral immune responses to rhinovirus infection in differentiated airway epithelial cells. Primary bronchial epithelial cells (BECs) from 16 patients with GOLD stage II or III COPD were differentiated at the air-liquid interface and infected ex vivo with rhinovirus (RV)-A1 or medium control (baseline). Cell lysates and supernatants were harvested post-infection. (a) IFNB, IFN $\lambda 1$ and IFN $\lambda 2 / 3$ (b) 2'-5' OAS, PKR and viperin mRNA expression in cell lysates at $72 \mathrm{~h}$ was measured by quantitative PCR. (c) IFN- $\beta$, IFN- $\lambda 1$ and IFN $\lambda$ $2 / 3$ proteins were measured at $72 \mathrm{~h}$ in cell supernatants by ELISA. Data represents individual patients and analysed by Wilcoxon rank sum test (baseline versus RV) or Mann Whitney $U$ test (RV frequent exacerbators versus RV infrequent exacerbator). ${ }^{*} p<.05 ;{ }^{*} p<0.01$. ns $=$ non-significant. 
a. Baseline

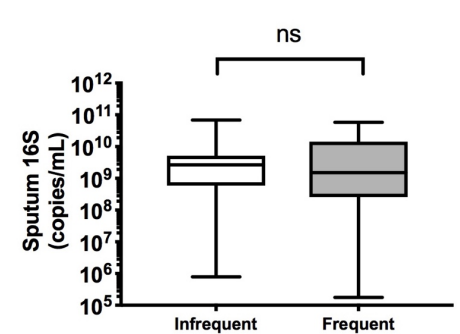

b. Exacerbation

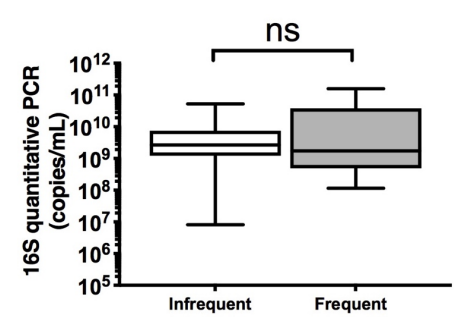

C. 2 weeks

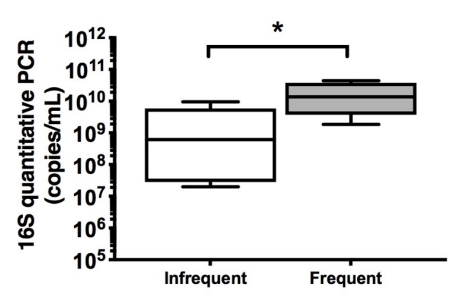

Figure 4: COPD patients with frequent exacerbations have increased bacterial loads during virus associated naturally occurring exacerbations. A cohort of patients with COPD were monitored prospectively. Patients were stratified according to exacerbation frequency in the preceding year with patients who experienced $\geq 2$ exacerbation episodes classified as 'frequent'. Sputum samples were taken at presentation with exacerbation associated with positive virus detection and 2 weeks during exacerbation. Sputum bacterial loads were measured by $16 \mathrm{~S}$ quantitative PCR at (a) baseline (b) exacerbation and (c) 2 weeks. Data shown as median (IQR) and analysed by Mann Whitney U test. ${ }^{*} p<0.05 . n s=$ non-significant. 
a.

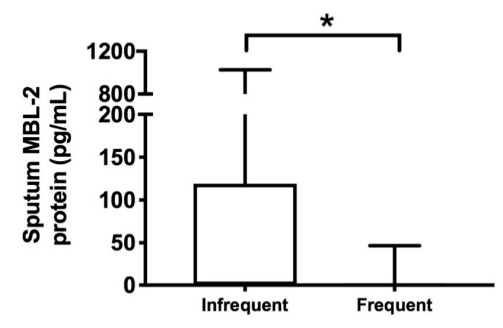

b.

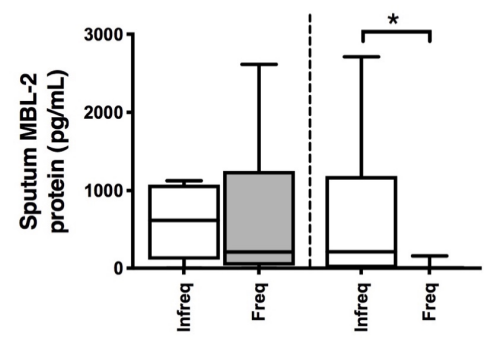

C.

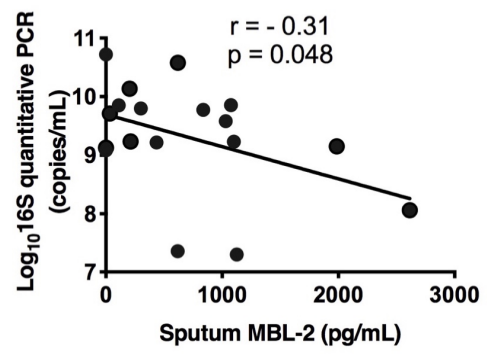

Figure 5: COPD patients with frequent exacerbations have reduced airway mannose-binding lectin 2 levels which correlate negatively with bacterial loads during virus associated exacerbations. Sputum protein concentrations of mannose binding lectin at (a) stable state (b) during virus associated exacerbation. (c) Correlation of sputum bacterial loads with sputum protein levels of mannose-binding lectin (MBL)-2. In (a)\&(b) data displayed as box and whisker plots showing median (line within box), IQR (box) and minimum to maximum (whisker) and statistical comparisons were made using Mann Whitney $U$ test. In (c), correlation analysis used was nonparametric (Spearman's correlation). ${ }^{*} p<0.05$. ns $=$ non-significant. 


\section{$\underline{\text { References }}$}

1. Seemungal TA, Donaldson GC, Paul EA, Bestall JC, Jeffries DJ, Wedzicha JA. Effect of exacerbation on quality of life in patients with chronic obstructive pulmonary disease. American journal of respiratory and critical care medicine. 1998;157(5 Pt 1):1418-1422.

2. Donaldson GC, Seemungal TA, Bhowmik A, Wedzicha JA. Relationship between exacerbation frequency and lung function decline in chronic obstructive pulmonary disease. Thorax. 2002;57(10):847-852.

3. Singanayagam A, Schembri S, Chalmers JD. Predictors of mortality in hospitalized adults with acute exacerbation of chronic obstructive pulmonary disease. Annals of the American Thoracic Society. 2013;10(2):81-89.

4. Hurst JR, Vestbo J, Anzueto A, et al. Susceptibility to exacerbation in chronic obstructive pulmonary disease. The New England journal of medicine. 2010;363(12):11281138.

5. Soler-Cataluna JJ, Martinez-Garcia MA, Roman Sanchez P, Salcedo E, Navarro M, Ochando R. Severe acute exacerbations and mortality in patients with chronic obstructive pulmonary disease. Thorax. 2005;60(11):925-931.

6. Seemungal T, Harper-Owen R, Bhowmik A, et al. Respiratory viruses, symptoms, and inflammatory markers in acute exacerbations and stable chronic obstructive pulmonary disease. American journal of respiratory and critical care medicine. 2001;164(9):1618-1623.

7. Rohde G, Wiethege A, Borg I, et al. Respiratory viruses in exacerbations of chronic obstructive pulmonary disease requiring hospitalisation: a case-control study. Thorax. 2003;58(1):37-42.

8. Mallia P, Message SD, Gielen V, et al. Experimental rhinovirus infection as a human model of chronic obstructive pulmonary disease exacerbation. Am J Respir Crit Care Med. 2011;183(6):734-742.

9. Hsu AC, Parsons K, Moheimani F, et al. Impaired Antiviral Stress Granule and IFNbeta Enhanceosome Formation Enhances Susceptibility to Influenza Infection in Chronic 
Obstructive Pulmonary Disease Epithelium. American journal of respiratory cell and molecular biology. 2016;55(1):117-127.

10. Baines KJ, Hsu AC, Tooze M, Gunawardhana LP, Gibson PG, Wark PA. Novel immune genes associated with excessive inflammatory and antiviral responses to rhinovirus in COPD. Respiratory research. 2013;14:15.

11. Kan OK, Ramirez R, MacDonald MI, et al. Human Metapneumovirus Infection in Chronic Obstructive Pulmonary Disease: Impact of Glucocorticosteroids and Interferon. The Journal of infectious diseases. 2017;215(10):1536-1545.

12. Mallia P, Footitt J, Sotero R, et al. Rhinovirus infection induces degradation of antimicrobial peptides and secondary bacterial infection in chronic obstructive pulmonary disease. Am J Respir Crit Care Med. 2012;186(11):1117-1124.

13. George SN, Garcha DS, Mackay AJ, et al. Human rhinovirus infection during naturally occurring COPD exacerbations. The European respiratory journal : official journal of the European Society for Clinical Respiratory Physiology. 2014.

14. Patel IS, Seemungal TA, Wilks M, Lloyd-Owen SJ, Donaldson GC, Wedzicha JA. Relationship between bacterial colonisation and the frequency, character, and severity of COPD exacerbations. Thorax. 2002;57(9):759-764.

15. Pizzichini E, Pizzichini MM, Leigh R, Djukanovic R, Sterk PJ. Safety of sputum induction. The European respiratory journal. Supplement. 2002;37:9s-18s.

16. Vogelmeier CF, Criner GJ, Martinez FJ, et al. Global Strategy for the Diagnosis, Management, and Prevention of Chronic Obstructive Lung Disease 2017 Report. GOLD Executive Summary. American journal of respiratory and critical care medicine. 2017;195(5):557-582.

17. Mallia P, Webber J, Gill SK, et al. Role of airway glucose in bacterial infections in patients with chronic obstructive pulmonary disease. The Journal of allergy and clinical immunology. 2017. 
18. Footitt J, Mallia P, Durham AL, et al. Oxidative and Nitrosative Stress and Histone Deacetylase-2 Activity in Exacerbations of COPD. Chest. 2016;149(1):62-73.

19. Hackett TL, Singhera GK, Shaheen F, et al. Intrinsic phenotypic differences of asthmatic epithelium and its inflammatory responses to respiratory syncytial virus and air pollution. Am J Respir Cell Mol Biol. 2011;45(5):1090-1100.

20. Hackett TL, Warner SM, Stefanowicz D, et al. Induction of epithelial-mesenchymal transition in primary airway epithelial cells from patients with asthma by transforming growth factor-beta1. American journal of respiratory and critical care medicine. 2009;180(2):122-133.

21. Singanayagam A, Glanville N, Girkin JL, et al. Corticosteroid suppression of antiviral immunity increases bacterial loads and mucus production in COPD exacerbations. Nat Commun. 2018;9(1):2229.

22. Bartlett NW, Walton RP, Edwards MR, et al. Mouse models of rhinovirus-induced disease and exacerbation of allergic airway inflammation. Nat Med. 2008;14(2):199-204.

23. Slater L, Bartlett NW, Haas JJ, et al. Co-ordinated role of TLR3, RIG-I and MDA5 in the innate response to rhinovirus in bronchial epithelium. PLoS pathogens. 2010;6(11):e1001178.

24. Cox MJ, Turek EM, Hennessy C, et al. Longitudinal assessment of sputum microbiome by sequencing of the $16 \mathrm{~S}$ rRNA gene in non-cystic fibrosis bronchiectasis patients. PloS one. 2017;12(2):e0170622.

25. Lin CL, Siu LK, Lin JC, et al. Mannose-binding lectin gene polymorphism contributes to recurrence of infective exacerbation in patients with COPD. Chest. 2011;139(1):43-51.

26. Hurst JR, Donaldson GC, Wilkinson TM, Perera WR, Wedzicha JA. Epidemiological relationships between the common cold and exacerbation frequency in COPD. Eur Respir J. 2005;26(5):846-852. 
27. Djukanovic R, Harrison T, Johnston SL, et al. The effect of inhaled IFN-beta on worsening of asthma symptoms caused by viral infections. A randomized trial. Am J Respir Crit Care Med. 2014;190(2):145-154.

28. Sethi S, Evans N, Grant BJ, Murphy TF. New strains of bacteria and exacerbations of chronic obstructive pulmonary disease. The New England journal of medicine. 2002;347(7):465-471.

29. Garcha DS, Thurston SJ, Patel AR, et al. Changes in prevalence and load of airway bacteria using quantitative PCR in stable and exacerbated COPD. Thorax. 2012;67(12):10751080.

30. Molyneaux PL, Mallia P, Cox MJ, et al. Outgrowth of the bacterial airway microbiome after rhinovirus exacerbation of chronic obstructive pulmonary disease. American journal of respiratory and critical care medicine. 2013;188(10):1224-1231.

31. Fidler KJ, Hilliard TN, Bush A, et al. Mannose-binding lectin is present in the infected airway: a possible pulmonary defence mechanism. Thorax. 2009;64(2):150-155.

32. Rantala A, Lajunen T, Juvonen R, et al. Mannose-binding lectin concentrations, MBL2 polymorphisms, and susceptibility to respiratory tract infections in young men. The Journal of infectious diseases. 2008;198(8):1247-1253.

33. Endeman $\mathrm{H}$, Herpers $\mathrm{BL}$, de Jong BA, et al. Mannose-binding lectin genotypes in susceptibility to community-acquired pneumonia. Chest. 2008;134(6):1135-1140.

34. Shi L, Takahashi K, Dundee J, et al. Mannose-binding lectin-deficient mice are susceptible to infection with Staphylococcus aureus. J Exp Med. 2004;199(10):1379-1390.

35. Neth O, Jack DL, Dodds AW, Holzel H, Klein NJ, Turner MW. Mannose-binding lectin binds to a range of clinically relevant microorganisms and promotes complement deposition. Infection and immunity. 2000;68(2):688-693.

36. Mandal J, Malla B, Steffensen R, et al. Mannose-binding lectin protein and its association to clinical outcomes in COPD: a longitudinal study. Respiratory research. 2015;16:150. 
37. Dicker AJ, Crichton ML, Cassidy AJ, et al. Genetic mannose binding lectin deficiency is associated with airway microbiota diversity and reduced exacerbation frequency in COPD. Thorax. 2017.

38. Hodge $\mathrm{S}$, Hodge $\mathrm{G}$, Jersmann $\mathrm{H}$, et al. Azithromycin improves macrophage phagocytic function and expression of mannose receptor in chronic obstructive pulmonary disease. American journal of respiratory and critical care medicine. 2008;178(2):139-148.

39. Karppinen S, Vuononvirta J, He Q, Waris M, Peltola V. Effects of Rhinovirus Infection on Nasopharyngeal Bacterial Colonization in Infants With Wild or Variant Types of MannoseBinding Lectin and Toll-Like Receptors 3 and 4. J Pediatric Infect Dis Soc. 2013;2(3):240-247.

40. Hodge S, Matthews G, Dean MM, et al. Therapeutic role for mannose-binding lectin in cigarette smoke-induced lung inflammation? Evidence from a murine model. American journal of respiratory cell and molecular biology. 2010;42(2):235-242.

41. Thomas BJ, Porritt RA, Hertzog PJ, Bardin PG, Tate MD. Glucocorticosteroids enhance replication of respiratory viruses: effect of adjuvant interferon. Scientific reports. 2014;4:7176.

42. Eddleston J, Lee RU, Doerner AM, Herschbach J, Zuraw BL. Cigarette smoke decreases innate responses of epithelial cells to rhinovirus infection. American journal of respiratory cell and molecular biology. 2011;44(1):118-126.

43. Han MK, Quibrera PM, Carretta EE, et al. Frequency of exacerbations in patients with chronic obstructive pulmonary disease: an analysis of the SPIROMICS cohort. The Lancet. Respiratory medicine. 2017;5(8):619-626. 


\section{Acknowledgements:}

Funding: Wellcome Trust Clinical Research Training Fellowship (grant number WT096382AIA) Imperial College Healthcare Trust Biomedical Research Centre grant (P33132); Academy of Medical Sciences and Wellcome Trust Starter Grant; Medical Research Council Program Grant G0600879; British Medical Association H.C. Roscoe Fellowships; BLF/Severin Wunderman Family Foundation Lung Research Program Grant P00/2; Imperial College and NIHR BRC funding scheme; the NIHR Clinical Lecturer funding scheme

\section{Author contributions:}

Conception and Design: AS, SLL, JF, SLJ, NWB, PM

Experimental work: AS, SLL, MC, MT, LJF, EB, JG, PV, PSP, KSN, AR, JF, NWB, PM

Writing of manuscript: All authors

Guarantor: AS 